\title{
A opção intergovernamental do Mercosul e a reforma do Protocolo de Ouro Preto
}

\author{
Maria Claudia Drummond ${ }^{1}$
}

\section{Resumo}

O trabalho discute a metodologia intergovernamental adotada pelos negociadores do Mercosul e suas consequências para o desenvolvimento do processo de integração. Nesse contexto, abordam-se a questão de uma possível reforma do Protocolo de Ouro Preto e os desdobramentos para a estrutura institucional do bloco, decorrentes da instalação do Parlamento do Mercosul.

Palavras-chave: Integração regional. Intergovernamental. Supranacionalidade.

\section{De Assunção a Ouro Preto}

Ao decidir constituir um mercado comum que deveria estar estabelecido em 31 de dezembro de 1994, o Tratado de Assunção, firmado em 26 de março de 1991, determinou, em seu Artigo 3º, um "período de transição", que se estenderia desde a sua entrada em vigor até a data estipulada para a constituição do mercado comum. Para esse período, ficou estabelecida também uma estrutura orgânica, prevista no Capítulo II, a qual, segundo estipula o Artigo 18, seria objeto de uma reunião extraordinária dos Estados-Partes para estabelecer a “[...] estrutura institucional definitiva dos órgãos de administração do Mercado Comum, assim como as atribuições específicas de cada um deles e seu sistema de tomada de decisões" (COMISSÃO PARLAMENTAR CONJUNTA DO MERCOSUL, 2005, p. 18.).

Recebido em 05.03.2011.

Aprovado em 25.04.2011.

1 Doutora em História das Relações Internacionais pela Universidade de Brasília e Consultora Legislativa do Senado Federal para a área de Relações Exteriores e Mercosul. Pesquisadora Associada do Departamento de Ciência Política da Universidade de Brasília e Professora do Instituto Legislativo Brasileiro. Autora do livro A democracia desconstruída: o déficit democrático nas relações internacionais e os parlamentos da integração (2010). Email:_claudiadrummond9@yahoo.com.br. 
O desenvolvimento do processo deflagrado pelo Tratado de Assunção nos anos seguintes demonstraria, no entanto, que a meta de conformar um mercado comum em apenas quatro anos, conforme haviam pactuado os Chefes de Estado da República da Argentina, da República Federativa do Brasil, da República do Paraguai e da República Oriental do Uruguai, não seria alcançada em tão curto espaço de tempo, por razões, cuja análise foge ao objetivo deste trabalho. Não obstante, ao final do segundo semestre do ano de 1994, foi efetivamente convocada conferência diplomática pela Presidência Pro Tempore brasileira, realizada em Brasília, com o fito de aprovar um documento a ser firmado em Ouro Preto, em 17 de dezembro de 1994 e que tratava da estrutura institucional do Mercosul. Iniciava-se, então, a fase da união aduaneira, onde as exceções à tarifa externa comum, a famosa TEC, eram abundantes e a elas agregava-se uma "lista de adequação", da qual constavam produtos que os países não desejavam incluir nem mesmo no regime da área de livre comércio.

Assim, após quatro anos de existência, o processo de integração não alcançara a meta do mercado comum, resultando em uma área de livre comércio pontuada de exceções e de uma união aduaneira extremamente imperfeita.

Não é de admirar, portanto, que um dos parágrafos do Preâmbulo do Protocolo de Ouro Preto expresse, de forma inequívoca, a decisão tomada pelos governos de aterem-se a uma estrutura institucional mínima, porém aberta a futuras transformações, considerando que é parte da essência de processos de integração a revisão contínua de suas instituições, para adequá-las aos sucessivos estágios de desenvolvimento do projeto integracionista. Declarava o Preâmbulo: “[...] atentos para a dinâmica implícita em todo processo de integração e para a conseqüente necessidade de adaptar a estrutura institucional do Mercosul às mudanças ocorridas; [...]"(COMISSÃO PARLAMENTAR CONJUNTA DO MERCOSUL, 2005, p. 34).

\section{A opção intergovernamental do Mercosul}

Os negociadores do Mercosul optaram por instituições de natureza claramente intergovernamental para o bloco. Pensavam eles que os órgãos e mecanis- 
mos que viessem a ser definidos para o Mercosul deveriam refletir os avanços reais da integração, em vez de se esperar que eles gerassem as circunstâncias que contribuiriam para a sua efetividade. "A forma deve seguir a função e não o contrário", pensavam os negociadores (BARBOSA, 1994, p. 1). ${ }^{2}$

A sistemática intergovernamental, já adotada pelo Tratado de Assunção, é reiterada pelo Protocolo de Ouro Preto em diversas oportunidades. O Artigo 2 dispõe que seus órgãos com capacidade decisória, a saber, o Conselho do Mercado Comum, o Grupo Mercado Comum e a Comissão de Comércio, esta última uma criação do Protocolo, têm natureza intergovernamental (COMISSÃO PARLAMENTAR CONJUNTA DO MERCOSUL, 2005, p. 35).

Mais adiante, o Artigo 37, ao explicitar o sistema de tomada de decisões, consensual $^{3}$ e com direito a veto pela ausência de qualquer Estado- Parte, não deixa dúvida quanto ao âmbito jurídico de inserção da integração: direito internacional clássico. Por fim, ao Capítulo IV, sobre a aplicação interna das normas emanadas dos órgãos do Mercosul, não falta clareza quanto à possibilidade de aplicabilidade direta das normas consensuadas no desenrolar do processo negociador. O Artigo 40, alínea (i), singelamente determina que os Estados-Partes adotarão as medidas necessárias para a incorporação das normas aprovadas ao ordenamento jurídico nacional e as comunicarão à Secretaria Administrativa do Mercosul (outro órgão inserido na estrutura administrativa do Mercosul por força do Artigo 1 do Protocolo de Ouro Preto). O Artigo 42 poderia confundir os mais incautos, ao determinar que as normas emanadas dos órgãos decisórios do Mercosul são obrigatórias para os Estados-Partes, assemelhando-se às normas de direito derivado da União Europeia. Tratar-se-ia, entretanto, para alguns autores, de mera aplicação do princípio pacta sunt servanda (GOBBI, 2001, p. 128.).

2 O Embaixador Rubens Barbosa foi Coordenador-Nacional da Seção Brasileira do Grupo Mercado Comum.

3 Hugo Gobbi assinala que a adoção do consenso e não da unanimidade permite alguma flexibilidade ao processo decisório, já que faculta a um Estado abster-se de se pronunciar sobre uma proposição, que ainda assim poderá ser aprovada, desde que nenhum dos Estados-Partes se oponha a ela. (GOBBI, 2001, p. 127). 
Não se contempla, portanto, à luz de Ouro Preto, um construto político semelhante ao idealizado pelos pais fundadores da União Europeia, no qual se mimetizava a divisão de poderes presente nos Estados nacionais e onde, por força da "constitucionalização" do processo, dar-se-ia também o salto para a sua "parlamentarização" (WEILER, 1999; COSTA, 2001).

À luz do Tratado de Assunção, a estrutura institucional do bloco compreendia, como órgãos decisórios, um Conselho do Mercado Comum (CMC), integrado pelos Ministros de Relações Exteriores e Ministros da Economia ou Fazenda dos Estados-Partes, e um Grupo Mercado Comum (GMC), órgão executivo do Mercosul, composto por representantes dos Ministérios das Relações Exteriores, da Economia ou Fazenda e seus equivalentes, e do Banco Central. O Protocolo de Ouro Preto agregou a estes, a Comissão de Comércio, órgão encarregado de velar pela aplicação dos instrumentos de política comercial comum acordados pelos Estados-Partes para o funcionamento da união aduaneira. Os chamados "órgãos não decisórios", ou “consultivos”, são a Comissão Parlamentar Conjunta (CPC), hoje substituída pelo Parlamento do Mercosul, ${ }^{4}$ o Foro Consultivo Econômico-Social (FCES), entidade representativa da sociedade civil, e a Secretaria Administrativa do Mercosul (SAM), mais tarde transformada em Secretaria do Mercosul, dotada de um Setor de Assessoria Técnica.

O Protocolo de Ouro Preto constituiu, do ponto de vista da legitimidade democrática do processo de integração, um salto qualitativo, ao incluir na estrutura orgânica do Mercosul a Comissão Parlamentar Conjunta e ao atribuir-lhe competências (Artigos 22 a 27). Ademais, a criação de um Foro Consultivo Econômico-Social, “órgão de representação dos setores econômicos e sociais” (Artigo 28) configurou sensível esforço, da parte dos negociadores, para sanar, pelo menos em parte, o déficit democrático presente em processos de integração.

Quando das negociações daquele diploma internacional, os governos decidiram atribuir personalidade jurídica ao Mercosul, para que o bloco pudesse atuar externamente como uma unidade. Pensava-se em suas negociações futuras com

\footnotetext{
4 Por força da Decisão 23/05, do Conselho do Mercado Comum, de dezembro de 2005.
} 
terceiros países ou grupos de países, como a União Europeia, mais particularmente na Área de Livre Comércio Sul-Americana, a ALCSA, que se propunha àquela época.

Por sua vez, a opção intergovernamental feita pelos Estados-Partes do Mercosul e a ausência de uma ordem jurídica específica baseada nos tratados não deixam dúvida quanto à inexistência, no bloco, de um complexo de normas do tipo comunitário, no formato do modelo das Comunidades Europeias, cujo conjunto dos Tratados Constitutivos o Tribunal de Justiça elevou a posição equivalente à de “carta constitucional." (VENTURA, 2003).

Por conseguinte, não há, tendo em vista o modelo adotado pelo Mercosul, cuja “[...] dinâmica é tão flexível que mais parece ser o fruto de um simples entendimento entre governos" (VENTURA, 2003, p. 126), a possibilidade de sua "constitucionalização" e muito menos de sua "parlamentarização" pela via de decisões judiciais que favoreçam um equilíbrio institucional na integração, semelhante ao mecanismo de checks and balances presente nos sistemas de tripartição de poderes, a exemplo do ocorrido no caso do Parlamento Europeu.

\section{Explorando algumas premissas teóricas}

Que implicações tem para o processo de integração a escolha do modelo intergovernamental como sua base política e jurídica em detrimento da metodologia comunitária da União Europeia?

Hugo Javier Gobbi estuda em profundidade o modelo intergovernamental e a sua influência na construção do Mercosul. Assinala que este modelo tem por base os conceitos da escola realista, alimentando-se "d'une conception pessimiste de l'humanité, selon laquelle la sécurité est une valeur suprême qui guide l'action politique des hommes" (GOBBI, 2001, p. 35-36). 
A esta abordagem pessimista opõem-se as visões pacifistas idealistas, cujas raízes não estão distantes dos ensinamentos encontrados em várias religiões e correntes filosóficas. ${ }^{5}$

O trabalho de Stanley Hoffmann retoma os conceitos de high politics e low politics para explicar a integração com supranacionalidade nas áreas não polêmicas e altamente técnicas (low politics), excluindo-a, porém, daquelas esferas onde possam estar em jogo temas percebidos como do mais alto interesse nacional (high politics). (ROSAMOND, 2000, p. 77).

Para refutar essa teoria, é importante notar que há indícios de que não foram apenas os condicionantes econômicos e comerciais que levaram os Estados-Partes da União Europeia a optarem pelo seu alargamento, ao incorporarem à União doze novos membros. Àqueles se somaram, indubitavelmente, considerações de ordem política e estratégica, como as questões de segurança.

Com efeito, se o bem comum nacional encontra-se indissoluvelmente ligado ao bem-estar de toda a humanidade, fato que se tornou patente por ocasião do trágico episódio de 11 de setembro de 2001, quanto mais, em uma perspectiva regional, estaria o interesse nacional vinculado ao que se passa no "entorno" de um país. Nesse raciocínio, é possível que a situação de pobreza, geradora de instabilidade institucional e de caos social, com os espaços daí decorrentes abertos à

5 Gobbi refere-se ao seguinte trecho da Encíclica Pacem in Terris, do Papa João XXIII: "Cumpre ter presente, a este propósito, que o poder público não foi constituído para encerrar os súditos dentro das fronteiras nacionais, mas para tutelar, antes de tudo, o bem comum nacional. Ora, este faz parte integrante do bem comum de toda a família humana”. (GOBBI, 2001, p. 38).

Ver também, no contexto dos ensinamentos da Religião Baháí, a máxima universalista de Baháu'lláh, seu fundador: "Que não se vanglorie quem ama seu próprio país, mas sim, quem ama a o mundo inteiro. A Terra é um só país e o gênero humano, seus cidadãos” (EPÍSTOLAS..., 1983, p. 186).

A noção encontra-se também em textos dos filósofos estóicos, anteriores ao cristianismo, dos quais a seguinte passagem do Imperador Marco Aurélio constitui belo exemplo: "Pensa sempre no liame que une todas as coisas no Universo e em sua mútua dependência. Todas as coisas estão interligadas umas com as outras e por esta razão vinculam-se por laços de amizade, pois elas estão em relação umas com as outras devido à unidade de todas as substâncias". (AURÉLIO, 1995, p. 65). 
prática do crime perpetrado tanto em âmbito nacional como transnacional, acabe por produzir, entre as elites decisórias de um Estado, a percepção de que o império da ordem e do bem-estar nos países vizinhos constitui objetivo prioritário do seu próprio interesse nacional. ${ }^{6}$ No caso da União Europeia, a instituição de um fundo comum, destinado a beneficiar os países menos desenvolvidos, não mereceu estudos das correntes realistas, mas encaixa-se nas formulações idealistas.

Segundo a visão intergovernamentalista, os Estados soberanos, principais atores no cenário internacional, lançam-se à integração a partir do reconhecimento de que as vantagens da cooperação e da identificação de interesses comuns superam os custos da situação de conflito. Mas em linhas gerais, na perspectiva intergovernamental, os Estados devem esforçar-se por fazer valer, acima da visão regional, o interesse nacional. Dessa noção decorre, naturalmente, o raciocínio segundo o qual a preservação da soberania nacional constitui um princípio essencial a ser observado ao longo das negociações da integração. Ademais, para os realistas, as decisões concernentes à formulação da política externa pertencem à esfera governamental, não cabendo maior participação das populações, ainda que se esteja tratando de um processo de integração regional, cujos resultados tendem a produzir profundos impactos na estrutura produtiva dos países envolvidos e no quotidiano de suas populações.

Quanto ao caso específico dos países da América Latina, já por diversas vezes nos referimos, ao longo deste trabalho, à pronunciada importância por eles conferida à noção de soberania nacional, que emerge indissoluvelmente ligada às suas raízes históricas e que até hoje permanece como princípio basilar de sua cultura política. O estudo dos parlamentos latino-americanos de integração, como o Parlamento Andino e o Centro-Americano, mostra que os países membros da Comunidade Andina, da mesma forma que os Estados-Partes do Sistema de Integração Centro-Americano, sucumbiram à tentação de reproduzir, em sua estrutura insti-

\footnotetext{
6 As seguintes palavras do Embaixador José Botafogo Gonçalves elucidam este ponto: “[...] é uma temeridade imaginar que o Brasil conseguirá alcançar plena estabilidade e desenvolvimento em meio a um continente sul-americano empobrecido do ponto de vista econômico, instável do ponto de vista político e desequilibrado do ponto de vista social" (GONÇALVES, 2002, p. 154).
} 
tucional, desde o início da integração, aspectos do construto político que caracteriza a União Europeia. Ali figuram elementos de supranacionalidade, que, entretanto, em vista da falta de real vontade política por parte dos governos latino-americanos, não funcionam a contento e acabam por debilitar toda a construção integracionista.

A metodologia intergovernamental, por seu turno, esbarra forçosamente em suas próprias limitações, porquanto a partir do momento em que os governos passam a ter a percepção de que o interesse nacional coincide com o bem-estar do vizinho, faz-se necessária uma radical transformação na própria abordagem da integração. É nesse ponto que se deveria operar a mudança de patamar, em primeiro lugar, de um olhar nacional para a percepção da região em seu conjunto; e em segundo, o salto da utilização de típicos instrumentos intergovernamentais de cooperação, de direito internacional clássico, tais como o veto, em direção a mecanismos decisórios mais elaborados.

Nesse contexto, é útil recordar a adoção, pelos países membros da então Comunidade Europeia, do sistema de votação por maioria qualificada no Conselho de Ministros, estabelecido pelo Ato Único Europeu, de modo a possibilitar a conformação do mercado único. Essa iniciativa correspondeu a uma opção dos Estados, a partir das preferências manifestadas por três de seus mais importantes membros - França, Reino Unido, e Alemanha - que pensavam utilizar os instrumentos da integração para alavancar as políticas econômicas, de cunho neoliberal, que naquele momento interessava-lhes implantar. ${ }^{7}$

Contudo, é inegável a centralidade dos Estados nacionais nas formulações que determinam os destinos da integração. As negociações conducentes às revisões dos Tratados ocorrem em âmbito intergovernamental e as entidades supranacionais são criadas pelos próprios governos, que lhes delimitam as competências.

Porém dois aspectos, não discutidos pelos realistas ou neorrealistas, merecem menção pela sua importância para a análise que aqui se desenvolve.

Sobre a conexão entre realismo e intergovernamentalismo em processos de integração regional, ver a rica discussão em Rosamond (2000). 
O primeiro refere-se à dinâmica de que se reveste o conceito de "interesse nacional". Muito embora a definição do que seja o interesse nacional ainda se vincule ao contexto da percepção do Estado soberano de sua posição relativa no âmbito do sistema de Estados, esse conceito é hoje matizado, nos processos de integração, por valores como "generosidade" e "solidariedade", de modo a sanar as inevitáveis assimetrias que simplesmente impossibilitariam a cooperação entre os sócios. Exemplo dessa linha de pensamento é a chamada "diplomacia de generosidade", adotada pelo governo do Presidente Luiz Inácio "Lula” da Silva, no contexto da integração da América do Sul. ${ }^{8}$

Outro aspecto que escapa às análises calcadas nos conceitos da escola realista clássica é o papel desempenhado pelos grupos de interesse e pelas articulações levadas a cabo na esfera da política interna dos países.

Entre os teóricos do intergovernamentalismo (intergovernamentalismo liberal), Andrew Moravcsik contribui de forma enriquecedora para a análise aplicada à integração europeia, ao explorar a crescente interface entre a política interna e as decisões atinentes às relações exteriores dos Estados.

Segundo esse autor, uma vez que o interesse primordial dos governos é a sua própria manutenção no poder, e dado que esse objetivo exige o apoio de uma forte aliança de partidos, eleitores, grupos de interesse e burocracias, é precisamente das demandas desses grupos que emerge o conjunto de diretrizes de política externa que os países expressam nos foros das organizações internacionais. "An understanding of domestic politics is a precondition for, not a supplement to, the analysis of strategic interaction among states" (ROSAMOND, 2000, p. 137).

8 Ver a exposição do então candidato à Presidência da República, Luiz Inácio Lula da Silva, em reunião conjunta das Comissões de Relações Exteriores e de Defesa Nacional da Câmara e do Senado, em 19 jun. 2002, quando discorreu sobre seu plano de governo no tocante às relações exteriores do Brasil, e afirmou que "[...] o tipo de atenção que dispensarmos à Argentina, país no qual deveremos multiplicar atitudes de solidariedade e de generosidade [...]". Ver também entrevista do Ministro das Relações Exteriores, Celso Amorim, ao Jornal Zero Hora, em 9 dez. 2004. 
Não são essas, entretanto, as únicas considerações de que se valem os países para a formulação de suas decisões no marco dos processos de integração. Premissas vinculadas aos interesses nacionais perenes, como aquelas que emergem da percepção que tem o Estado de si próprio e do papel que lhe deve caber no cenário regional e mundial, permeiam os processos decisórios integracionistas. Um exemplo disso é a conformação da União de Nações Sul-Americanas - Unasul, projeto fortemente apoiado pela Venezuela, originado da ideia da Comunidade Sul-Americana de Nações (CASA), avançada pelo Brasil, que desejava reafirmar a sua liderança no continente.

Paulo Roberto de Almeida analisa a arquitetura institucional pela qual optaram os negociadores do Mercosul. Compara-a à metodologia escolhida pelos "pais fundadores" da União Europeia, que esteve, ao longo do processo de integração, em constante tensão entre pulsões contraditórias, às vezes em direção ao método intergovernamental e, às vezes, voltando-se à metodologia comunitária, caracterizada por aspectos de supranacionalidade. Recorda que, por motivos fundamentalmente pragmáticos e utilitários, prevaleceram os fortes aspectos de supranacionalidade, consubstanciados no Ato Único Europeu.

Afigura-se de interesse a elucidação das características estruturais do famoso modelo "comunitário" adotado para a integração europeia, conforme enumeradas pelo autor (ALMEIDA, 1994, p. 23):

- presença de instituições independentes dos EstadosMembros (Comissão, Parlamento, Tribunal de Justiça);

- métodos decisórios supranacionais (possibilidade de votação no Conselho segundo o princípio majoritário, superando eventuais oposições de Estados individuais);

- um sistema próprio de recursos e a transferência de certas competências à Comunidade; $\mathrm{e}$

- normas que vinculam diretamente os indivíduos, agentes econômicos e empresas.

Escrevendo no momento em que o Mercosul preparava a arquitetura institucional que figuraria no Protocolo de Ouro Preto, firmado em 17 de dezembro de 1994 e que acompanharia a implantação da união aduaneira, o autor opina que não 
se poderia impulsionar no Mercosul, sem consideráveis riscos políticos, inclusive e principalmente de perda de credibilidade internacional, um processo de definição supranacional de instituições e métodos como os acima enumerados (ALMEIDA, 1994, p. 23). Pensamento similar expressa Jorge Fontoura ao defender a conveniência do timing político adotado pelos negociadores do Mercosul, sem o qual o Tratado de Assunção “[...] de há muito teria sido denunciado, ou, mais à nossa moda, simplesmente olvidado, nas infinitas gavetas da retórica pan-americana” (FONTOURA, 2003, p. 274).

Assim, o Protocolo de Ouro Preto veio a reiterar a natureza intergovernamental do Mercosul e a metodologia do consenso para os seus processos decisórios.

\section{A revisão de Ouro Preto: um olhar sobre o conjunto da região}

Assim como figurara no Tratado de Assunção dispositivo a possibilitar a futura reforma dos órgãos por ele estabelecidos, também o art. 47 do Protocolo de Ouro Preto determina a convocação de conferência diplomática pelos Estados-Partes, quando julgarem oportuno, com o objetivo de revisar a estrutura institucional do Mercosul, bem como as atribuições de seus órgãos.

Por esse motivo, dez anos após a sua assinatura, diante do que especialistas identificaram como o "esgotamento da agenda comercial do Mercosul", falava-se em se proceder à reforma do Protocolo. Já àquela época, eram claros os indícios de que chegara o tempo de se adequar a estrutura institucional consagrada por Ouro Preto à nova realidade do bloco.

Ao apagar das luzes do governo de Fernando Henrique Cardoso, escrevia o Embaixador José Botafogo Gonçalves, ex-Representante Oficial do Presidente da

9 Palavras do Embaixador Eduardo Amadeo, representante argentino na Comissão de Representantes Permanentes do Mercosul (CRPM), por ocasião do seminário Desafios Institucionales para el Mercosur, Montevidéu, 27 e 28 de agosto de 2004, organizado pela Fundação Friedrich Ebert (FESUR). 
República para o Mercosul, referindo-se à crise financeira do final dos anos noventa, que“. [...] a estrutura institucional vigente no Mercosul se mostrou muito limitada para evitar, abrandar ou remediar situações de impasse e conflito entre os governos." E mais: “Quanto aos receios do Brasil ante maior ingerência dos demais países sobre sua liberdade de ação, devemos avaliar muito cuidadosamente se os custos de resistir a um mínimo de supranacionalidade não estão se tornando elevados demais a essa altura da evolução do Mercosul [...]” (GONÇALVES, 2002, p. 157).

A percepção que se instalara entre os negociadores brasileiros do Mercosul, ao final do governo Fernando Henrique Cardoso, concernente a uma maior institucionalização do Mercosul, perdurou ao longo do primeiro mandato do governo Lula, ao termo do qual a criação da Unasul viria a desviar e enfraquecer o foco da política externa brasileira.

É importante destacar, por exemplo, o Comunicado dos Presidentes, emitido por ocasião da Reunião de Cúpula de Puerto Iguazú, em 8 de julho de 2004, que, em seu ponto 12, expressa que os Presidentes dos Estados-Partes do Mercosul tomaram nota da proposta, apresentada na XXVI Reunião do Conselho do Mercado Comum, referente "[...] a la conveniencia de identificar los aspectos del Protocolo de Ouro Preto que podrían ser motivo de revisión a la luz de los recientes avances institucionales del MERCOSUR". ${ }^{10}$

Os avanços institucionais aqui mencionados referiam-se à recente criação de órgãos no Mercosul, destinados a adotar um enfoque regional e não puramente nacional para a integração. Entre eles, a Comissão de Representantes Permanentes do Mercosul (CRPM), estabelecida por meio da Decisão do Conselho do Mercado Comum $N^{o}$ 11/03, composta de membros designados pelos respectivos governos para representá-los junto à CRPM e à Secretaria, como órgãos permanentes do Mercosul.

A criação da figura do presidente da CRPM, que seria uma personalidade política e não da carreira diplomática, de nacionalidade de um dos Estados-Partes,

${ }^{10}$ Disponível em <http://www.mercosur.org.uy/>. Acesso em: 2 ago. 2010. 
podendo representar o Mercosul frente a terceiros Estados, parecia refletir a intenção de conferir ao bloco uma identidade a ser projetada externamente e que ao mesmo tempo pudesse lançar um olhar neutro e não limitado pelos interesses nacionais ao conjunto da sub-região. ${ }^{11}$

Também nessa época, as assimetrias entre os países, mencionadas no Preâmbulo do Protocolo de Ouro Preto - "[...] e atentos para a necessidade de uma consideração especial para países e regiões menos desenvolvidos no MERCOSUL” - passam a ser tratadas, com a elaboração de estudos sobre um fundo comum para o bloco por um grupo de especialistas (Grupo de Alto Nível sobre Convergência Estrutural no Mercosul e Financiamento do Processo de Integração), criado pela Decisão 19/04 do Conselho do Mercado Comum que estipulou, no art. $2^{\circ}$, que o Grupo seria coordenado pela Presidência da CRPM e contaria com a assistência daquela Comissão. ${ }^{12}$ A criação do Fundo para a Convergência Estrutural e Fortalecimento da Estrutura Institucional do Mercosul, por meio da Decisão CMC 18/05, regulamentado mediante a Decisão CMC 25/05, confere ao Mercosul certos aspectos que caracterizam a metodologia supranacional utilizada pela União Europeia, não só pela própria postura adotada pelos governos dos Estados-Partes, ao decidirem tomar iniciativas no sentido de suavizar as pronunciadas diferenças entre os países, como também pela própria composição diferenciada do Fundo, cujos aportes se baseiam na média histórica do Produto Interno Bruto (PIB) do Mercosul, por país. A distribuição dos recursos do FOCEM para projetos apresentados pelos distintos países é feita na proporção inversa aos seus aportes. Assim, o Brasil contribui com 70\% do montante total anual do Fundo, mas aos projetos apresentados pelo País são direcionados apenas $10 \%$ dos recursos. Foi a Presidência da CRPM que envidou esforços junto aos Estados-Partes para a plena implementação do FOCEM, realizando negociações junto aos Parlamentos nacionais para a pronta incorporação, aos ordenamentos jurídicos internos, das duas decisões do Conselho do Mercado Comum.

${ }^{11}$ Exerceram o mandato de presidente da CRPM Eduardo Duhalde e Carlos Alvarez, ambos, políticos argentinos. O cargo foi substituído pelo de "Alto Representante-Geral do MERCOSUL" em dezembro de 2010, tendo sido indicado para ocupá-lo o Embaixador brasileiro Samuel Pinheiro Guimarães.

${ }^{12}$ Disponível em <http://www.mercosur.int/>. Acesso em 1 ago. 2010. 
Nesse mesmo período, a Secretaria ganhou um Setor de Assessoria Técnica (SAT), com a contratação, por concurso público, de dois consultores para a área de Direito Internacional e dois para a área de Economia, "[...] que deveriam atuar de uma perspectiva comum e contribuir para a consolidação do MERCOSUL" (Decisão 30/02 do CMC). ${ }^{13}$ Não obstante haverem normas posteriores retirado do SAT parte de sua independência e autonomia, assegurando aos Estados-Partes certo grau de intervenção nos trabalhos dos consultores, é importante registrar a presença da Secretaria como órgão técnico, incumbido de identificar, à luz de uma perspectiva comum, as carências, eventuais lacunas normativas e dificuldades específicas enfrentadas pelo processo de integração.

Pode-se concluir, por conseguinte, que, a partir do ano 2000 e, mais especificamente, entre os anos de 2002 e 2005, verificou-se clara movimentação, por parte dos governos dos Estados-Membros, no sentido de adotar iniciativas que, ainda que tímidas, conferiam ao Mercosul certas características típicas da metodologia comunitária, que contempla aspectos de supranacionalidade.

Em primeiro lugar, cabe mencionar a criação de um órgão permanente presidido por uma figura política, com mandato de dois anos e independente dos governos dos Estados-Partes podendo, por conseguinte, atentar para os interesses da região como um todo e transcender a estreita visão limitada ao interesse nacional imediato. Em segundo lugar, instituiu-se um fundo comum - o FOCEM - característica do modelo supranacional.

A essas duas iniciativas, somaram-se a criação de um número de Reuniões Especializadas congregando setores específicos da sociedade civil dos Países-Membros, do Setor de Assessoria Técnica da Secretaria, do "Programa de Trabalho do MERCOSUL 2004-2006", ${ }^{14}$ que previa a criação do Parlamento do Mercosul, levando a supor que havia, à época, alguma dose de vontade política, por parte dos governos dos Estados-Partes, de dinamizar a estrutura institucional

\footnotetext{
${ }^{13}$ Disponível em: <http://www.mercosur.int>. Acesso em: 2 ago. 2010.

${ }^{14}$ Adotado pelo Conselho do Mercado Comum por meio da Decisão No 26 de 2003. Disponível em: <http://www.mercosur.org.uy/>. Acesso em: 23, jul. 2010.
} 
do Mercosul de maneira a conferir-lhe um olhar voltado ao bem-estar do bloco como um todo.

Por ocasião do seminário "Desafios Institucionales para el Mercosur", que se realizou em Montevidéu, em 28 de agosto de 2004, o Embaixador José Botafogo Gonçalves recordou a experiência inovadora, em matéria de institucionalidade da integração, adotada pelos negociadores do Mercosul, que consistia em construir as instituições à medida que a realidade do bloco o exigisse. Efetivamente, por meio dessa estratégia, o Mercosul evitou sucumbir à tentação do [...] mimetismo institucional" com a União Europeia e com outros esquemas de integração da América Latina. ${ }^{15}$ Contudo, o Embaixador estimou que, naquele momento, o bloco atravessava período de transição que deveria levá-lo a adotar uma visão regional, cujo principal instrumento seria entidades com responsabilidade também regional.

$\mathrm{Na}$ opinião dos especialistas reunidos naquela ocasião em Montevidéu, como: José Botafogo Gonçalves, Eduardo Amadeo, Gustavo Margariños, Félix Peña e Marco Aurélio Garcia, ${ }^{16}$ se o Mercosul não puder contar com instituições fortes, acabará por perder a confiabilidade nas negociações com outros blocos e países. Dava-se, portanto, naquele momento histórico, uma "combinação favorável de densidade de necessidade e densidade de oportunidades", nas palavras de Félix Peña, que justificaria plenamente a revisão da estrutura institucional do bloco.

Na mesma ocasião, Reginaldo Arcuri, então diretor da Secretaria do Mercosul, referiu-se a "ajustes na estrutura institucional do Mercosul", cujo formato deveria estar decidido até dezembro de 2004.

\footnotetext{
${ }^{15}$ Informação verbal.

${ }^{16}$ Embaixador José Botafogo Gonçalves, ex-Embaixador do Brasil na Argentina; Embaixador Eduardo Amadeo, da Argentina, Chefe de Gabinete do Presidente da Comissão de Representantes Permanentes do Mercosul; Embaixador Gustavo Margariños, do Uruguai, ex-Secretário Executivo da Associação Latino-Americana de Integração; Professor Marco Aurélio Garcia, assessor internacional do Presidente do Brasil; Professor Félix Pena, exEmbaixador e professor do Centro Argentino para as Relações Internacionais (CARI) e da Universidade Tres de Febrero.
} 
Na realidade, as negociações conducentes ao "Protocolo de Ouro Preto II" levadas a cabo ao longo da presidência pro tempore brasileira no segundo semestre de 2004, não resultaram na adoção de novo documento. Porém, a ata da XXVII Reunião do Conselho do Mercado Comum, realizada em Belo Horizonte, em 15 e 16 de dezembro de 2004, determinou que o tema seguisse em exame no Grupo Mercado Comum. ${ }^{17}$

\section{Protocolo de Ouro Preto e o Parlamento do Mercosul}

Ao longo de todo o ano de 2004, ao mesmo tempo em que muito se falava em uma possível revisão das instituições do Mercosul por meio de um "Ouro Preto II", que marcaria a celebração da primeira década de vida da estrutura institucional criada para o bloco pelo Protocolo de Ouro Preto, temia-se que, afinal, a reforma não passasse do que se chamou de uma revisão "cosmética” do Protocolo, evitando temas que afetassem as susceptibilidades dos Estados-Partes, como o processo decisório por consenso e que constituíam as verdadeiras travas ao aprofundamento da integração.

À Comissão Parlamentar Conjunta (CPC), transformada, pela Decisão no 49/04 do Conselho do Mercado Comum, em comissão preparatória para realizar todas as ações necessárias à instalação do Parlamento do Mercosul, interessava acompanhar o desenrolar das negociações, uma vez que a nova estrutura institucional deveria, minimamente, contemplar as disposições do Acordo Interinstitucional celebrado entre o Conselho e a CPC, que conferiam a esta última competência consultiva no tocante às normas em negociação nos órgãos decisórios do Mercosul.

Posteriormente, as normas do Acordo Interinstitucional seriam incorporadas ao texto do Projeto de Protocolo Constitutivo do Parlamento do Mercosul

\footnotetext{
${ }^{17}$ MERCOSUL/CMC/ATA no 02/04. Disponível em: <http:// www.mercosur.org.uy/>. Acesso em: 23 jan. 2011.
} 
encaminhado à consideração do Conselho do Mercado Comum $^{18} \mathrm{e}$ aprovado por meio da Decisão no 23/05, firmada em Montevidéu, em 9 de dezembro de 2005.

No entanto, com a falta de acordo no tocante à reforma do Protocolo de Ouro Preto, a competência consultiva do Parlamento, bem como outras de suas funções, permanecem pendentes de regulamentação.

Com efeito, à luz do disposto no Protocolo Constitutivo do Parlamento do Mercosul, o Conselho é o principal interlocutor do órgão parlamentar. Cumpriria, então, adequar os dispositivos do Protocolo de Ouro Preto à presença do Parlamento na estrutura institucional do bloco para nele incorporar o diálogo a ser encetado entre as duas instituições.

A competência consultiva, pela qual a Assembleia Parlamentar emite parecer não vinculativo aos projetos de normas em negociação no Mercosul que requeiram aprovação legislativa, configura a sua mais importante função.

\footnotetext{
${ }^{18}$ Artigo 4:

[...] 12. Com o objetivo de acelerar os correspondentes procedimentos internos para a entrada em vigor das normas nos Estados Partes, o Parlamento elaborará pareceres sobre todos os projetos de normas do MERCOSUL que requeiram aprovação legislativa em um ou vários Estados Partes, em um prazo de noventa dias a contar da data da consulta. Tais projetos deverão ser encaminhados ao Parlamento pelo órgão decisório do MERCOSUL, antes de sua aprovação.

Se o projeto de norma do MERCOSUL for aprovado pelo órgão decisório, de acordo com os termos do parecer do Parlamento, a norma deverá ser enviada pelo Poder Executivo nacional ao seu respectivo Parlamento, dentro do prazo de quarenta e cinco dias, contados a partir da sua aprovação.

Nos casos em que a norma aprovada não estiver de acordo com o parecer do Parlamento, ou se este não tiver se manifestado no prazo mencionado no primeiro parágrafo do presente literal a mesma seguirá o trâmite ordinário de incorporação.

Os Parlamentos nacionais, segundo os procedimentos internos correspondentes, deverão adotar as medidas necessárias para a instrumentalização ou criação de um procedimento preferencial para a consideração das normas do MERCOSUL que tenham sido adotadas de acordo com os termos do parecer do Parlamento mencionado no parágrafo anterior. O prazo máximo de duração do procedimento previsto no parágrafo precedente, não excederá cento e oitenta dias corridos, contados a partir do ingresso da norma no respectivo Parlamento nacional [...]"
} 
No entanto, o Parlamento vê-se impedido de implementá-la, em virtude da sua falta de regulamentação pelo Conselho.

Foi apenas em dezembro de 2008 que o Conselho do Mercado Comum adotou a Decisão no 47/08, que constitui um Grupo de Alto Nível sobre a Relação Institucional entre o Conselho do Mercado Comum e o Parlamento do Mercosul (GANREL), com vistas à elaboração de uma proposta relativa aos procedimentos de interação entre os dois órgãos. Curiosamente, ao contrário do que ocorreu por ocasião das negociações do Protocolo Constitutivo do Parlamento, quando a CPC foi transformada em "comissão preparatória”, desta feita, o Conselho contemplou apenas a participação, no GANREL, de representantes dos Estados-Partes designados pelas chancelarias nacionais, prevendo a possibilidade de eventual convite ao Parlamento para que se faça representar "quando se considere oportuno", com a finalidade de intercambiar opiniões. ${ }^{19}$

Em sua Ata nº 02 de 2009, o Conselho consignou a criação do Grupo de Alto Nível sobre a Relação Institucional entre o Conselho do Mercado Comum e o Parlamento do Mercosul, encarregado de elaborar uma proposta relativa a procedimentos de interação entre os dois órgãos, com vistas a garantir a eficiência do processo decisório regional e a agilização dos trâmites legislativos para a incorporação de normativa Mercosul que necessite aprovação dos respectivos Parlamentos nacionais. ${ }^{20} \mathrm{O}$ tema, entretanto, até agora não prosperou. É importante assinalar, entretanto, que também aos Parlamentos nacionais falta adotar o procedimento preferencial para as normas aprovadas de acordo com o parecer do Parlamento do Mercosul a que se refere o inciso 12 do art. 4. Apenas o Congresso Nacional brasileiro o fez, conforme o disposto no art. $4^{\circ}$ da Resolução nº 1, de 2007-CN.

Outras competências do Parlamento preveem iniciativas do Conselho e deveriam figurar entre as atribuições e funções do órgão máximo do Mercosul, estipuladas no artigo $8^{\circ}$ do Protocolo de Ouro Preto. Entre elas cite-se o inciso 13

\footnotetext{
${ }^{19}$ Disponível em: <http://www.mercosur.int>. Acesso em: 1 ago. 2010.

${ }^{20}$ Mercosur/CMC/Acta No 02/09. Disponível em: <http://www.mercosur.int>. Acesso em: 1 ago. 2010.
} 
do art. $4^{\circ}$ do Protocolo Constitutivo do Parlamento do Mercosul, à luz do qual o Conselho do Mercado Comum deverá informar semestralmente sobre o tratamento dado aos projetos de normas propostos pelo Parlamento.

\section{Conclusões}

A propalada reforma do Protocolo de Ouro Preto, que daria origem ao "Ouro Preto II", aproveitando a Reunião de Cúpula que se realizaria naquela cidade mineira por ocasião do décimo aniversário da assinatura do Protocolo, nunca vingou. ${ }^{21}$

Mesmo assim, no que concerne a avanços institucionais no Mercosul, os anos de 2000 a 2005 foram significativos, a partir de programas como o de Relançamento do Mercosul (2000), de Fortalecimento Institucional do bloco (2001), e do Programa de Trabalho do Mercosul 2004-2006 (2003). ${ }^{22}$

Já nos referimos também ao aspecto de permanência e de visão de conjunto que caracterizam a Comissão de Representantes Permanentes do Mercosul, o Setor de Assessoria Técnica da Secretaria e o FOCEM.

A Presidência da Comissão, entretanto, foi posteriormente extinta e substituída pela figura do "Alto Representante-Geral do MERCOSUL", ${ }^{23}$ designado pelo Conselho do Mercado Comum para um período de três anos, podendo seu mandato ser prorrogado por igual período, que desempenhará funções “[...] tendo em conta o interesse geral do MERCOSUL e o aprofundamento do processo de integração".

${ }^{21}$ Para sugestões quanto a uma reforma abrangente do Protocolo de Ouro Preto ver Mata Diz (2007).

${ }^{22}$ Disponível em: <http://www.mercosur.org.uy/>. Acesso em: 23 jul. 2010.

${ }^{23}$ Por meio da Decisão no 63 de 2010 do Conselho do Mercado Comum. Ver MERCOSUL/ CMC/DEC. No 63/10. Disponível em: <http://www.mercosur. org.uy/>. Acesso em: 23 fev. 2011.

${ }^{24}$ Artigo 4. 
Foi, porém, o Parlamento o órgão a avançar mais no sentido da adoção de uma percepção regional do Mercosul ao incorporar, em seu instrumento constitutivo, dois aspectos que remetem distintamente ao método supranacional. O primeiro deles é o processo decisório. O segundo é a sua composição.

Com efeito, é da essência das assembleias parlamentares o embate entre forças políticas diversas e o exercício do voto individual, por parlamentar e não por delegação. Não se concebe, assim, um parlamento cujas decisões devam, forçosamente, ser tomadas por consenso. Não é por outra razão que o art. 9 do Protocolo Constitutivo do Parlamento do Mercosul proclama a independência dos membros do Parlamento, que “[...] não estão sujeitos a mandato imperativo" e "atuarão com independência no exercício de suas funções”. ${ }^{25}$

Da mesma forma, para cumprir a sua função de instância de representação dos cidadãos dos Estados-Partes, o Protocolo Constitutivo do Parlamento prevê que as delegações nacionais devem estar conformadas de modo a refletir - ainda que de que maneira atenuada - as diferenças populacionais entre os países do bloco. A tendência, a partir daí, é a conformação de bancadas transnacionais em torno a um ideário definido, como a Bancada Progressista, já em atividade no Parlamento do Mercosul, a refletir a posição de completa independência do parlamentar em relação ao governo de seu país de origem. ${ }^{26}$ Tal tendência deverá se acentuar com a realização das eleições diretas dos parlamentares do Mercosul, também previstas no Protocolo.

Foge-se, dessa maneira, tanto ao espírito do consenso, consagrado pelo Protocolo de Ouro Preto, quanto à igualdade soberana entre os Estados, próprios ao método intergovernamental, para ingressarmos em lógica mais complexa, semelhante ao método comunitário adotado pela antiga Comunidade Europeia. ${ }^{27}$ É

${ }^{25}$ Ver art. 9 do Protocolo Constitutivo do Parlamento do Mercosul. Disponível em: <http://www2.camara.gov.br/atividade-legislativa/comissoes/comissoes-mistas cpcms/ parlamento.html/protocolo.html/protocoloparlamentoMercosul>. Acesso em: 23 fev. 2011.

${ }^{26}$ Ver entrevista do Deputado Dr. Rosinha. Disponível em: <http://www2. camara.gov.br/ agencia/noticias/139094.html>. Acesso em :23 fev. 2011.

${ }^{27}$ Criada pelo Tratado de Paris, de 1954 e de Roma, de 1957. 
importante assinalar que esse fato não implica qualquer tipo de sobreposição dos atos do Parlamento do Mercosul às decisões dos parlamentos nacionais, mas permite à assembleia funcionar como um parlamento e não como uma reunião de representantes governamentais. Pode-se afirmar, portanto, que a presença de órgão parlamentar no bloco impõe, em razão da própria natureza daquela instituição, a revisão de Ouro Preto.

Em conclusão, nota-se, da leitura de Decisões do Conselho do Mercado Comum emitidas a partir do ano 2000, claro movimento em direção a um novo patamar institucional para o bloco com vistas ao fortalecimento da capacidade de produção de propostas de políticas regionais, com referência até mesmo a uma "gestão comunitária"28 no tocante a temas fundamentais.

Tal adaptação da estrutura institucional do Mercosul aos avanços ocorridos no processo de integração, entretanto, nunca chegou a se concretizar. Esperemos que a reforma do Protocolo de Ouro Preto para a adequação da estrutura institucional do bloco à sua presente realidade, não se limite à criação do Alto Representante-Geral para o Mercosul, o que configuraria apenas a "reforma cosmética" que tanto se temia.

\section{Mercosur's intergovernmental option and the reform of the Protocol of Ouro Preto}

\section{Abstract}

The work discusses the intergovernmental method adopted by the negotiators of Mercosur and its consequences for the development of the integration process. In this context, it examines the question of a possible reform of the Protocol of Ouro Preto, particularly from the point of view of the impact of the creation of the Parliament of Mercosur on the bloc's institutional framework.

Keywords: Regional integration. Intergovernmental. Supranationality.

\footnotetext{
${ }^{28}$ Ver Decisão nº 63/10 do Conselho do Mercado Comum.
} 


\section{Referências}

ALMEIDA, Paulo Roberto. Mercosul e União Europeia: vidas paralelas? Boletim de Integração Latino-Americana, Brasília, n. 14, p. 16-25, jul./set. 1994.

AURÉLIO, Marco. Meditações. São Paulo: Iluminuras, 1995.

BARBOSA, Rubens Antônio. O Mercosul e suas instituições. Boletim de Integração Latino-Americana, Brasília, n. 14, p. 1-2, jul./set. 1994.

BATE-PAPO sobre o Parlasul com o deputado Dr. Rosinha. Agência Câmara de Notícias, Brasília, 26 ago. 2009. Disponível em: <http://www2. camara.gov.br/ agencia/noticias/139094.html>. Acesso em: 23 fev. 2011.

BRASIL. Câmara dos Deputados. Departamento de Taquigrafia, Revisão e Redação, Núcleo de Redação Final em Comissões. Notas Taquigráficas da Audiência Pública Conjunta da Comissão de Relações Exteriores e Defesa Nacional da Câmara dos Deputados e Comissão de Relações Exteriores e de Defesa Nacional do Senado Federal. Brasília, 2002, p. 15.

CARTA Encíclica Pacem in terris. A Santa Sé, Cidade do Vaticano, 11 abr. 1963. Disponível em: <http://www.vatican.va/holy_father/john_xxiii/ encyclicals/ documents/hf_j-xxiii_enc_11041963_pacem_po.html >>. Acesso em: 23 abr. 2005.

COMISSÃO PARLAMENTAR CONJUNTA DO MERCOSUL. Mercosul: legislação e textos básicos. Brasília: Senado Federal, 2005.

COSTA, Olivier. Le Parlement européen, assemblée délibérante. Bruxelas: Éditions de l'Université de Bruxelles, 2001.

DRUMMOND, Maria Claudia. A democracia desconstruída: o déficit democrático nas relações internacionais e os parlamentos da integração. Brasília: Senado Federal, 2010.

ENTREVISTA do Ministro das Relações Exteriores, Celso Amorim. Zero Hora, Porto Alegre, 9 dez. 2004. Disponível em: <http://www.mre.gov.br/ portugues/ politica_externa/discursos/discurso_detalhe.asp?D_DISCURSO=2525 $>$. Acesso em: 23 abr. 2005.

FONTOURA, Jorge. A evolução do sistema de solução de controvérsias - de Brasília a Olivos. In: COMISSÃO PARLAMENTAR CONJUNTA DO MERCOSUL E MINISTÉRIO DAS RELAÇÕES EXTERIORES. Solução de controvérsias no Mercosul. Brasília: Câmara dos Deputados, 2003. 
GOBBI, Hugo Javier. Démocratie et Intégration dans le Mercosur: le rôle da la Commission Parlementaire Conjointe. 2001. 349 folhas. Tese (Doutorado)Departamento de Ciências Políticas e Sociais, Faculdade de Ciências Econômicas, Sociais e Políticas, Universidade Católica de Louvain, 2001.

GONÇALVES, José Botafogo. Mercosul após 2002: propostas a partir de um testemunho pessoal. In: HUGUENEY FILHO, Clodoaldo; CARDIM, Carlos Henrique (Org.). Grupo de reflexão prospectiva sobre o Mercosul. Brasília: FUNAG, 2002.

MATA DIZ, Jamile Bergamaschine. Mercosur: orígen, fundamentos, normas y perspectivas. Curitiba: Juruá, 2007.

ROSAMOND, Ben. Theories of European Integration. Basingstoke: Palgrave, 2000.

VENTURA, Deisy. As assimetrias entre o Mercosul e a União Européia: os desafios de uma associação inter-regional. Barueri, SP: Manole, 2003.

WEILER, Joseph H. H. The Constitution of Europe: do the new clothes have an emperor? and other essays on European Integration. Cambridge: Cambridge University, 1999. 


\section{Para publicar na revista Universitas}

Relações Internacionais, entre no endereço eletrônico www.publicacoesacademicas.uniceub.br. Observe as normas de publicação, facilitando e agilizando o trabalho de edição. 